\title{
Design of Campus Smart Card System
}

\author{
Lv Weichun \\ Information Center \\ Suzhou Vocational University \\ Suzhou, China \\ lwc@jssvc.edu.cn
}

\begin{abstract}
With the fast development of campus informationization, the complexity of comsumption types and identification of college teachers and students also increases, which raises more strigent requirements to college management. This essay illustes the overall planning of campus Smart Card system, discussing the construction target and technical requirements of campus card system, designing the general frameworkd and putting forward the design plan of the construction of campus Smart Card system.
\end{abstract}

Keywords- campus smart card;Program design;Overall planning;System Platform

\section{ANALYSIS OF CURRENT SITUATION}

Nowadays, college students have various comsumption tyes, such as dining, shopping, purchasing water and electricity, surfing on the net, seeking medical advice and ect. Usually different consumption types are managed by different departments. Each maters the information of its own system, thus the information data could not be shared. However, colleges and universities are laying more and more attention on identification of persons inside the school so as to build safe campus. Therefore, to construct a centralized platform with one card to take the place of identification is of great necessity. This essay puts forward the overall planning of campus card system, which is implemented finally.

The so-called campus Smart Card system, in brief, is to have every teacher and student to possess a campus card, which could take the place of all or part functions of all previous identifications (including student's identity card, employee's card, library card, medical card and key card, etc.). With the campus card, teachers and students could go into all places, do business, do activities and purchase. And it could even realized auto-deposit with the bank card. Thus it could realize finally the ideal of "with one card in hand, you could go the campus around", meanwhile, it can also promote the process of informationizaiton and standardization of the management of all units and departments. Such managing module replaces the traditional comsumption management module and brings efficiency, convenience and safty to school management.

\section{ANALYSIS OF THE SYSTEM REQUIREMENTS}

\section{A. General requirements}

Construction project of campus Smart Card of colleges and universities should be based on systems of shared library, unified identification platform to construct "campus Smart Card" system centralized platform, which includes general management platform, identification platform, student's fingerprint registration and other subsystems.

With the advantage of college net resources, the campus card could identify student's card, employee's card, library card, medical card, computer card, breast card and etc.

With the wallet function of campus card, the carrier could consume at various comprehensive comsumption sites, for example, dining at the dining hall, purchasing in the supermarket, bathing in the bathroom, self-help washing, surfing on the net, paying fines of overdue books, self-help purchasing water and electricity. Thus the campus smart card with comprehensive comsumption could be realized.

Through the connection with the financial and bank systems, the campus card could realize the functions of deposit and transference, auto accounting, withholding remitting on campus, as well as comsumption inqury. Thus the campus card with financial service could be realized.

\section{B. Design requirements of the platform of software system}

The system adopts three-tier architecture: The user application and data are isolated by the middle tier (business logic layer and data access layer), which defines a series of interface specifications with unified standards. All data access should be audited and verified, which could ensure safe access to the database and prevent efficiently illegal access and tampering.

Redundant system data backup: Multilevel redundant data backup could increase efficiently the system's resistance ability to accidents. Redundant disk arrays, mulitilevel storage of the database and the application server's secondary storage of the data completely derived from the master server make the redundant data of the whole system sufficient and efficient.

Security measures of the system data: Mulitilevel backup storage of system data, secure and efficient data access mechanism, strict data access signin and signout function, all make the data access manageable and orderly, which could guarantee the system data to be in enough 
security and respond efficiently to the request of using the subsystem data.

\section{System selection and design requirements}

System selection of campus card is based on non-contact CPU card design, and meanwhile be compatible with Mifare series, financial card and cell phone card. The cards of the above mentioned systems could be used depending on the specific requirements, or while using a kind of card, compatible reading and writing of anther kind of card could be offered, so that the system could be updated or the card type be changed with the principle of using the old to protect the original investment efficacies as possible. Most devices could be transitted between the system using Mifare seires card and the system using CPU card to interchange the types of the card in use.

\section{SYSTEM ARCHITECTURE DESIGN AND APPLICATION SYSTEM DESIGN}

\section{A. Topology design of system network}

Supported by the college campus network, all kinds of the terminal devices adopt the design of combining 485 communication and TCP communication, which is in favor of constructing comprehensive network platform better, as well as save the investment on network devices. The comprehensive design sees Figure 1.

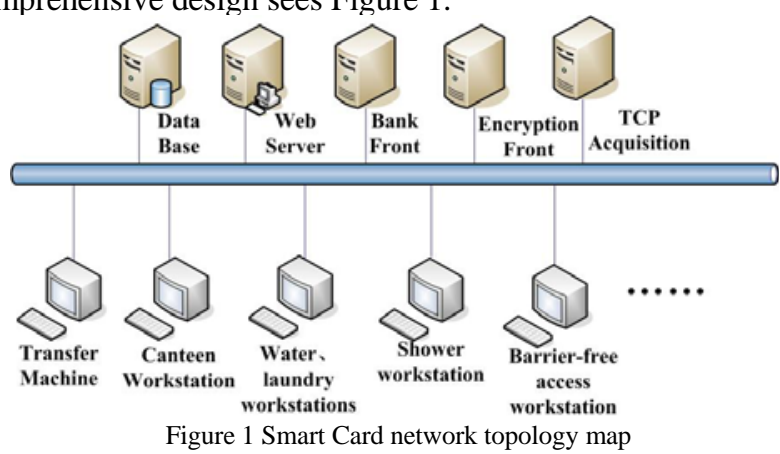

\section{B. 3-level platform architecture design}

The system architecture adopts 3-level platform architecture: Digital campus as Level 1 platform; bank, teaching, finance and campus card management center as Level 2 platform; all the application systems as Level 3 platform.

Level 1 platform: The share data center, unified indentificaiton and unified portal system of the digital campus serve as the core of data exchange and data share;

Level 2 platform: The bank network system interlinks the bank and the information center network through telecom DDN special, setting corresponding rules to realize point to point data communication, so that the users could deposit into the bank, inqury the balance of the bank card and daily business settlement. As the backbone communication platform of "campus Smart Card" system, the campus network mainly realizes various businesses on campus with the campus card.
Level 3 platform: Various application subsystems of this project and other application subsystem related to campus card.

\section{Access scheme of the third party (Figure 2)}

When connecting with a third party, the communication is based on TCP/IP network; the system softwares offer various interface implementation from Web Service interface tier, application process tier and card reader tier: Web Service standard method reference, industry-standard XML file exchange, service packet, secondary development SDK dynamic link library (DLL), protocol message packet switching, database view, and etc.. Flexible networking mode, variety and standardization of the interface offer solid foundation to the access of the third party.

\section{Smart Card Business Platform}

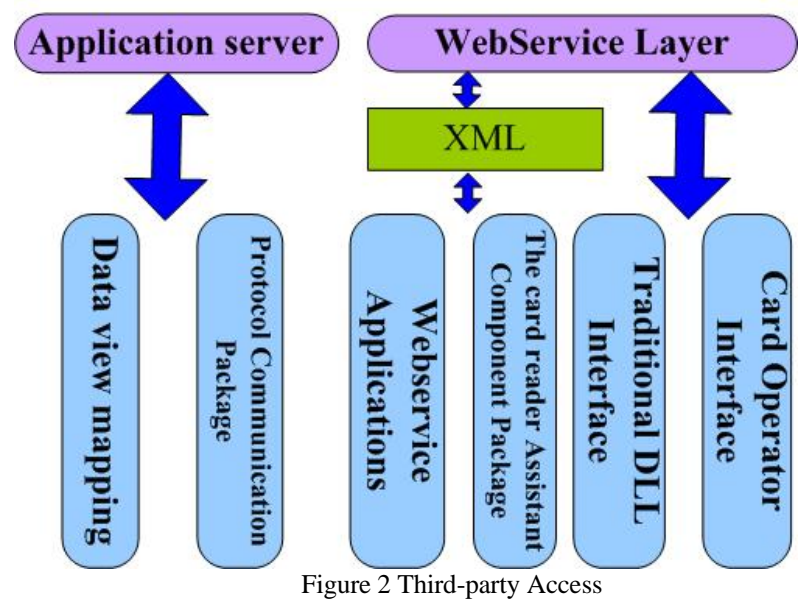

D. The design of Application platform

At present, the campus card applies widely in our school. The general application design sees the Figure 3

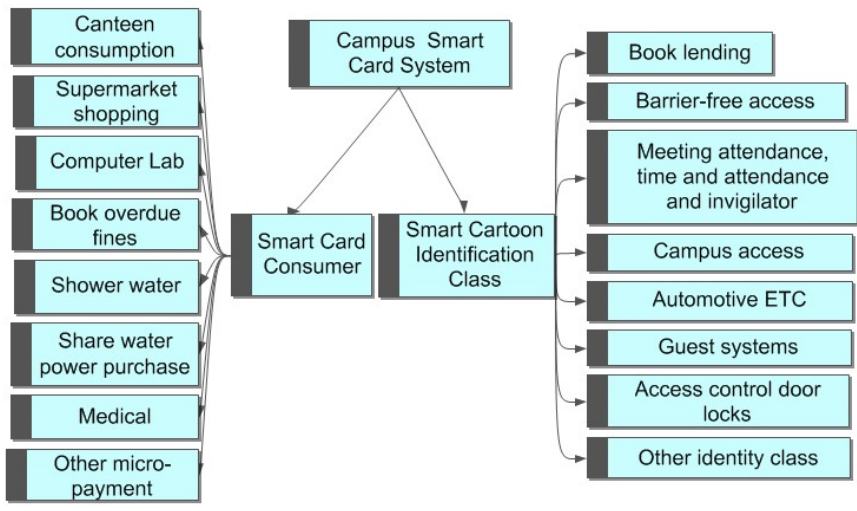

Figure 3 Smart Card application deployment

1) Financial trading platform of campus card

- Financial trading platform of campus Smart Card is mainly responsible for collection and comprehensive summary statistical treatment of the trading information of comsumptions in the card. 
System of financial trading application: Dining and other comsumptions, centralized control and other micropayments.

Payment function of campus card: It is mainly used at the dining hall, in the supermarket, micropayment, in the computer room, in the library and other places. It is to fulfill the electronic payment of various comsumptions on campus of the teachers and students.

- Comsumption with card is realized with the real ewallet, with perfect card information, secure terminal data collection mechanism and log management.

- It has the character of non-contact reading and faster reading spead. It could run offline. When the tolling POS runs offline, it could automatically judge whether there is balance in the card, whether the card is reported for loss or whether it has been written off without relying on the database of the host computer, i.e. it could verify the validity and legality of the card efficiently.

2) Identifying platform of campus Smart Card

- Identifying platform of campus Smart Card is mainly responsible for the summary and comprehensive settlement of the identified information in it.

- Identity authentication application: Identitiy authentication system, fingerprint authentication system, access control system, attendance system, personnel supervision, door access system, barrier-free access system, and etc.

- Fingerprint authentication system, with smart card as the storage media, adopts fingerprinted imbedded in smart card authentication technology to have electronic identity authentication. With the authentication module of "smart card + fingerprint", it could efficiently judge the sole relationship between the card and the possessor, avoiding helping others attending in cases of attendance, examination supervision, student's registration and other cases which require identity authentication, so as to increase the secure grades of identity authentication.

- Smart card access control and lock management system are mainly to safely and efficiently control access to the passage. Access control system is mainly divided into: entrance-exit inspection control, electronic lock access control, lock and channel director control.

- Attendance management system could realize the function of checking on work attendance, offering multiuser monitering and sound alarming. The function of checking on work attendance refers that it could make statistics of the card reading information when the employees going to and from work, and ultimately it could give the attendance information, absence information, and information of asking for leave and information of working overtime. This product could monitor at the same time the card reading information of many people and through the user terminal the personal's information could be read. If there were someone who uses the card illegally, the system will send audible alarm.

- $\quad$ Fingerprint meeting attendance is a set of meeting attendance system of fingerprint identification, computer network technology, integrated radio frequency card and biometric identification technology. What the working person should do is only to read the card on the machine, press his finger, then he is signed and has his identity authenticated. The uniqueness of fingerprints eradicates the manifestation of dishonesty, such as helping others attending, and ensures the justice and correctness of the attendance. Successfully matched, a piece of attendance message would be upload to the database.

- Barrier-free access system could realize 24-hour uninterrupted video monitoring and linkage channel control. When the holder enters or exits the channel and has his card read actively, the system could judge his validity quickly and correctly. The illegal identiy or those with no cards would be screened and meanwhile it could start the soundlight alarm and takes photos. So that it could avoid the low efficiency of traditional channel in checking personnel's identity and the crowdness thus caused. It could also prevent tailers and sneakers. In emergent cases it could also evacuate the personnel quickly.

\section{CONCLUSION}

The construction of campus Smart Card system is a unified comprehensive management system. Based on the requirement of digital campus and Smart Card, we proposed this design program after thorough investigation: It is designed with the advanced technology and based on prospective long-term programming; selection of the device modals is designed based on the prociples of reasonability and advancement, rational construction, protecting the original investment, guaranteeing steady performance, reliable operation and excellence-based openness and expansibility. Besides the normal processing ability of software and hardware, other factors such as plent of emergent real data, information transmission and storage security are also taken into consideration. What's more, in the design of the system, we stuck to always the principle of "avoiding manual intervention as possible". Most of the work was completed by the system itself. So that the system could run much more steadily, and be easier to operate and maintain, and easier for the users.

"Campus Smart Card” is an important part of "digital campus”. It realizes comprehensive consumption, identity authentication, financial service, public information service and other functions, which offers powerful data to excavating various information and offers safeguards to construction of intellectual campus.

\section{REFERENCES}

[1] Wu Hairong.Design of Campus Smart Card System[J].Journal of Ningxia University:Natural Science Edition,2002,23(4):346-349.

[2] Qiu Shuwei. Design and Implementation of Campus Card System Construction [J]. Journal of Hunan University of Technology, 2010, 24(4):61-64.

[3] Abolhassan Shamsaie, Jafar Habibi, Fatemeh Ghassemi.A Three -Tier Framework for P2P Applications.International Joural of Computer Science and Network Security.2007,7:55-70.

[4] Xu Wenshuan,Xin Yunwei.Design and Implementation of Middle Ware-Based E-Card System for Campus[J].Computer Engineering and Design,2007,28(7):1723-1726. 
[5] Zhou Yilu,Zhong Jian,Pu Xun.A Frame Work of Campus-Grid Service Based on Bank Card[J].Journal of Southwest University:NaturalScienceEdition,2007,29(3):160-163.

[6] Liu Dongming. The Design and Implementation of Campus Smart Card System in Hangzhou Academy of Scientific Professional Technology[D]. Shanghai:East China Normal University,2009:15-54.

[7] Liu Xinmei,Yang Qiuxiang,Liu Xinglai.Design of Campus Smart Card System and Its' Application in Educational Administration[J]. Journal of North University of China:Natural Science Edition,2007,28(2):134-137.
[8] DAI Hong-fang,FENG Xiang,XIAN Xiao-bing,CHEN Feng.Research and Practice of Business Intelligence in the Campus Card[J] .Microelectronics \& Computer,2012,29(7):175-179.

[9] SHANG Xin-Na,SUN Lian-Ying,PEMG Tao,LIU Chang.Campus Card Application System Based on Data Warehouse[J].Computer Systems \& Applications, 2012,21(3):20-23

[10] HU Rong.Construction and Practice of Campus One Card[J]. Research and Exploration in Laboratory, 2012,31(7):404-405. 